\title{
Failure analysis of isolation switch in transformer substation
}

\author{
Yi Xie ${ }^{1 *}$, Yaxia Qiao², Hao Zhang²and Hongjian Lou ${ }^{3}$ \\ ${ }^{1}$ State Grid Hunan Electric Power Company Limited Research Institute, Changsha, 410007, China \\ 2 China Electric Power Research Institute, Beijing, 100192, China \\ ${ }^{3}$ State Grid Zhejiang Electric Power Research Institute, Hangzhou, 410007, China
}

\begin{abstract}
To analyze the fault cause of metal parts of isolation switch, a series of tests including macro check, penetrate testing, hardness measurement, composition tests and metallographic observation have been carried out. The experimental results showed that the failure of connecting lever was caused by improper processing, which resulted in the limitation of cracking and stress corrosion cracking. Based on this, the corresponding noteworthy key points were put forward to avoid similar accidents.
\end{abstract}

\section{Introduction}

With the continuous expansion of the construction scale of UHV project, the types and quantity of UHV equipment are increasing explosively, and the new type of disconnector is its typical representative [1-3]. Due to its lower threshold of production, variety, production and installation is in place, each link is difficult to fully control and long exposure to the harsh natural outdoor environment, it is easy to break down, such as abnormal heating, poor contact and institutional fracture failure which greatly threatens the safety and reliability of the grid system[4-7].

In this paper, the fault of isolation switch caused by the failure of metal parts is studied, and the failure reason is found out by macro check, penetrate testing, hardness measurement, composition tests and metallographic observation, and the corresponding measures are also put forward.

\section{Experiment section}

The failed metal parts of isolation switch were collected from transformer substation in service. The morphologies and structures of the samples were analyzed by metallurgical microscopy (Zeiss microscope). The component measurement was conducted via desktop direct-reading spectrometer (Oxford corporation). The Brinell hardness test value were acquired from Brinell tester.

\section{Results and discussion}

\subsection{Connecting lever}

\subsubsection{Macro check and penetrant testing}

The connecting lever of isolation switch was severely cracked as shown in Fig.1. Massive cracks extend on the surface of connecting lever which was composed of $0 \mathrm{Cr} 18 \mathrm{Ni} 9$ austenite steel with hexagonal profile. Further penetrant testing results revealed that the longitudinal crack was as long as $300 \mathrm{~mm}$, accounting for about $72 \%$ of the total length of the connecting lever. There are also many transverse cracks on the middle surface of the connecting lever, as displayed in Fig.2.

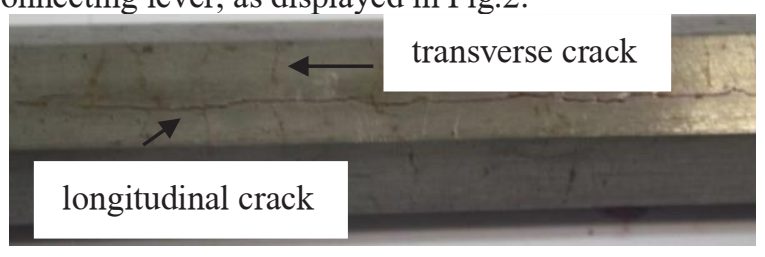

Fig. 1. Macroscopic feature of connecting lever.

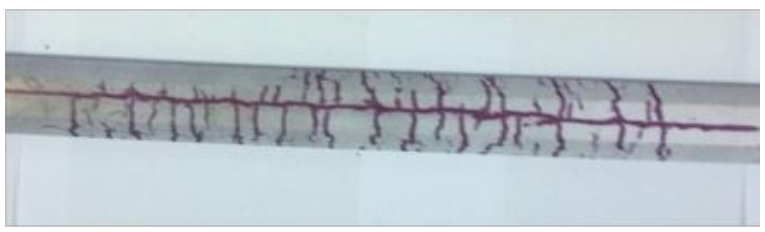

Fig. 2. Penetrant inspection of connecting lever.

\subsubsection{Component testing}

Table 1. Components of connecting lever.

\begin{tabular}{|c|c|c|}
\hline Element & Content/\% & Standard $/ \%$ \\
\hline $\mathrm{Si}$ & 2.67 & $\leqslant 1.00$ \\
\hline $\mathrm{Mn}$ & 3.06 & $\leqslant 2.00$ \\
\hline $\mathrm{Cr}$ & 15.62 & $18.00 \sim 20.00$ \\
\hline $\mathrm{Ni}$ & 6.35 & $8.00 \sim 11.00$ \\
\hline $\mathrm{Fe}$ & Remain & Remain \\
\hline
\end{tabular}

\footnotetext{
* Corresponding author: yxie001@126.com.cn
} 
As illustrated in Table 1, the component of the connecting lever was measured. The content of $\mathrm{Si}$ and $\mathrm{Mn}$ exceeds the upper limit of standard. However, the contents of $\mathrm{Cr}$ and $\mathrm{Ni}$ are lower than the lower limit of the standard. It indicates that the connecting lever material does not meet the standard requirements of GB/T 1220-2007 Stainless Steel.

\subsubsection{Hardness measurement}

The Brinell hardness of cracked connecting lever was measured. The result was shown in Table 2.

Table 2. Brinell hardness of connecting lever.

\begin{tabular}{|c|c|c|}
\hline Test number & Test Value/HB & \multirow{2}{*}{ Standard/HB } \\
\hline First & 264 & \multirow{2}{*}{$\leqslant 187$} \\
\hline Second & 262 & \\
\hline Third & 265 & \\
\hline Fourth & 268 \\
\hline Fifth & 264 \\
\hline
\end{tabular}

The hardness value of cracked connecting lever is between $262 \mathrm{HB}$ and $268 \mathrm{HB}$ which is much higher than the standard requirement of GB/T 1220-2007 Stainless Steel.

\subsubsection{Tensile strength and elongation test}

The tensile strength values of connecting lever were in the range of $449 \mathrm{MPa}$ to $475 \mathrm{MPa}$ which is far below $520 \mathrm{MPa}$ specified by the requirements of GB/T 1220 2007 Stainless Steel. And all the elongation test values of connecting lever were also not in conformity with standard requirements $(50 \%)$.

\subsubsection{Microstructure analysis}

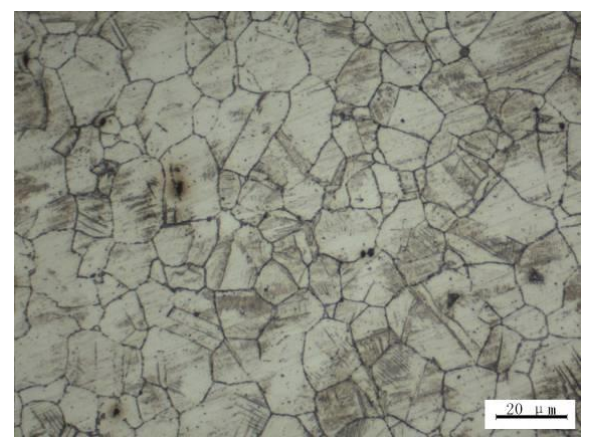

Fig. 3. The metallographic structure of connecting lever.

The microstructure of the connecting lever is combination of austenitic and carbide as shown in Fig.3, which conforms to the microstructure requirements of austenitic stainless steel. The microstructure of the longitudinal crack is shown in figure 4. The crack extends along the grain boundary and extends inward from the surface of the sample. The longitudinal crack is large and the transverse crack is small.

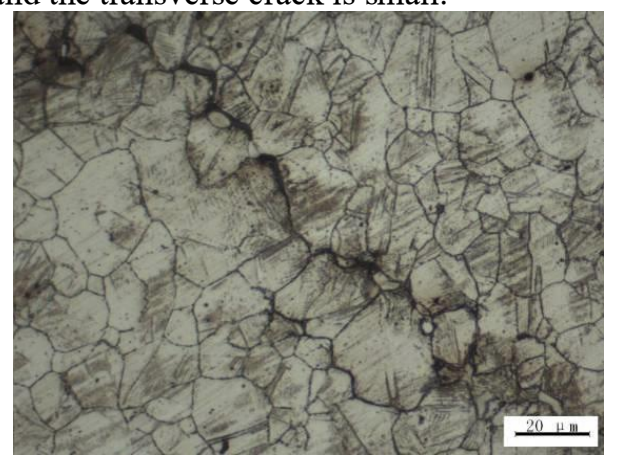

Fig. 4. The longitudinal crack picture of connecting lever.

\subsubsection{Cause analysis}

The austenitic stainless steel material is prone to aging cracking (also called delayed cracking) when the residual stress is not eliminated after processing. The processing of hexagonal connecting rod adopts the drawing technique, and the hardness exceeds the standard requirements which implying that the internal stress is large and the longitudinal crack conforms to the aging cracking characteristics.

Austenitic stainless steel is prone to stress corrosion under the condition of tensile stress corrosion. The connecting lever is in service condition of tensile stress, and contact with the external environment can provide corrosion medium. Considering that the transverse crack is densely distributed in the stress region (middle part of the connecting lever), it can be judged that the transverse crack is a stress corrosion crack. In addition, due to the low content of $\mathrm{Cr}$ and $\mathrm{Ni}$ of the connecting lever, the material composition does not meet the standard requirements of GB/1220-2007 Stainless Steel. It also has a great impact on the failure and cracking of the connecting lever.

The chemical elements, hardness, tensile strength, elongation of failed connecting lever do not meet the standard requirements which indicating the material is not qualified. The immediate cause of failure is aging crack and stress corrosion crack which is caused by improper processing.

\subsection{Universal joint}

\subsubsection{Macro check}

The two failed universal joint of isolation switch were shown in Fig.5 and Fig 6, respectively. There is corrosion on the surface of both samples, and the cracks are located in the directions of four o 'clock and eight o'clock of the outer ring. Observed from the side of disconnected universal joint, distortion occurs from the ball head to the part above the crack, as shown in Fig.5 Further inspection revealed that the fracture exhibits no deformation. 


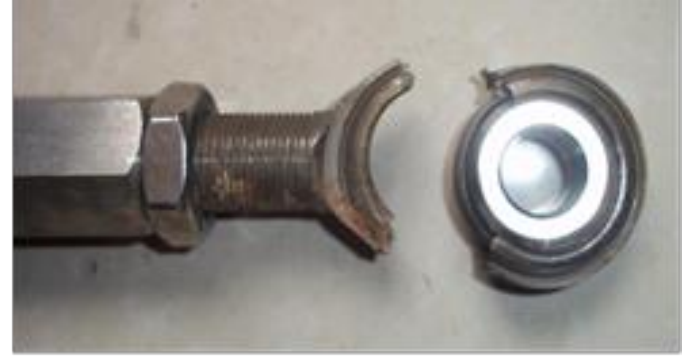

Fig. 5. The macroscopic feature of disconnected universal joint.

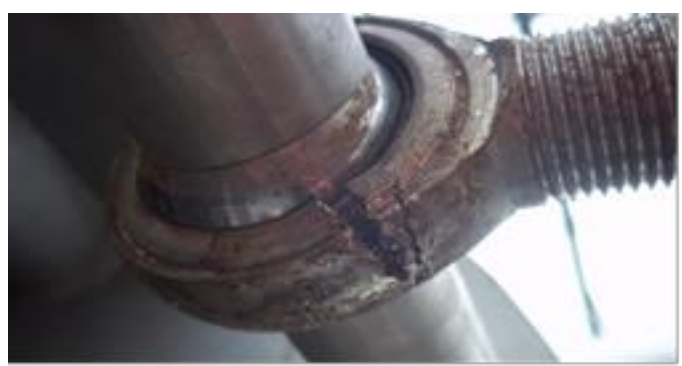

Fig. 6. The macroscopic feature of undisconnected universal joint.

\subsubsection{Component testing}

Table 3. Components of universal joint.

\begin{tabular}{|c|c|c|}
\hline Element & Content/\% & Standard/\% \\
\hline $\mathrm{Si}$ & 0.54 & $\leqslant 1.00$ \\
\hline $\mathrm{Mn}$ & 1.29 & $\leqslant 2.00$ \\
\hline $\mathrm{Cr}$ & 18.12 & $18.00 \sim 20.00$ \\
\hline $\mathrm{Ni}$ & 8.31 & $8.00 \sim 11.00$ \\
\hline $\mathrm{Fe}$ & Remain & Remain \\
\hline
\end{tabular}

The component testing results of the universal joint were shown in Table 3. All the content of elements are in accordance with the standard requirements of $\mathrm{GB} / \mathrm{T}$ 1220-2007 Stainless Steel.

\subsubsection{Hardness measurement}

The Brinell hardness of universal joint was measured. The result was shown in Table 4. The test values are distributed in the range of $135 \mathrm{HB}$ to $156 \mathrm{HB}$ which conform to the standard requirements of GB/T 12202007 Stainless Steel.

Table 4. Brinell hardness of universal joint.

\begin{tabular}{|l|l|l|}
\hline Test number & Test Value/HB & Standard/HB \\
\hline
\end{tabular}

\begin{tabular}{|c|c|c|}
\hline First & 143 & \multirow{2}{*}{$\leqslant 1 \leqslant 1$} \\
Second & 135 \\
\hline Third & 152 & \\
\hline Fourth & 149 & \\
\hline Fifth & 156 & \\
\hline
\end{tabular}

\subsubsection{Microstructure analysis}

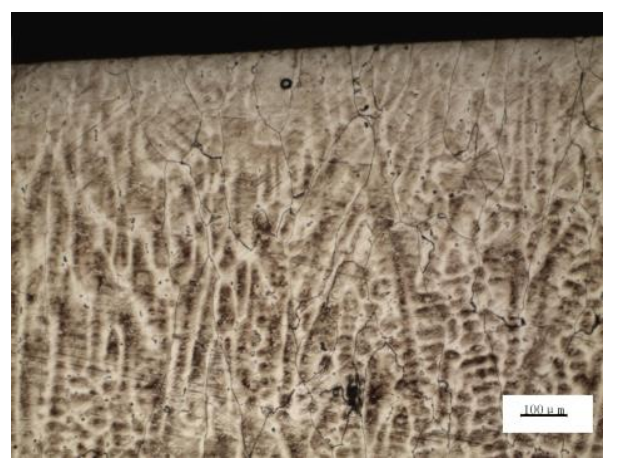

Fig.7. The metallographic structure of universal joint.

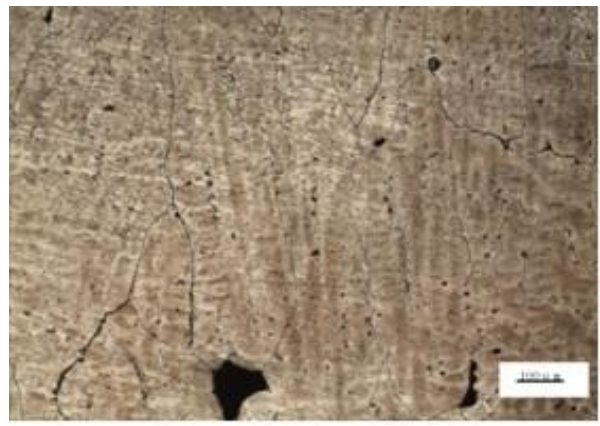

Fig.8. The picture of thick columnar crystal.

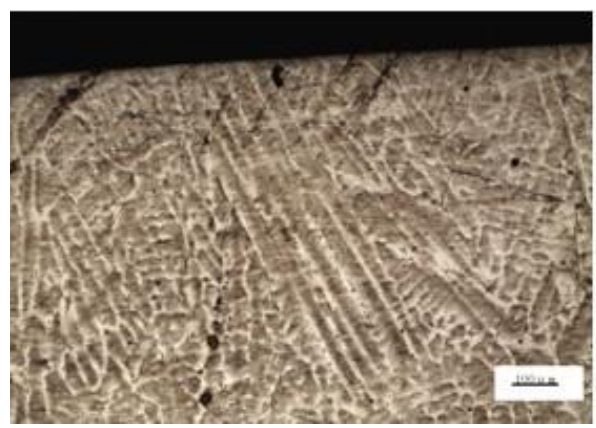

Fig.9. The picture of dentritic crystal.

The microstructure of the sample is austenite with coarse structure, as shown in Fig.7. There is equiaxed crystal at the edge, obvious columnar crystal inside. The dendrite solidification trace could be identified, as well as immaterial twins. typical as-cast austenitic structure, as shown in Fig. 8 and Fig.9. 
At the same time, there are multiple cracks in the microstructure. The cracks are generated from the edge and gradually grow into the tissue along the grain boundary, which is a typical intergranular crack, as shown in Fig. 10.

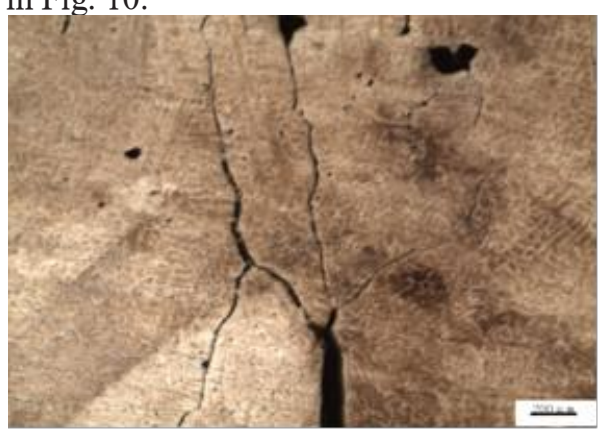

Fig.10. The picture of the intergranular crack in sample.

\subsubsection{Cause analysis}

According to the microstructure analysis, the actual material of universal joint is ZG0Cr18Ni9. In addition, the design requirements are forgings, the actual use is castings, the material is inconsistent with the design. The microstructure of cast steel is not uniform, there are structural defects such as element segregation, and its performance is much lower than that of machined stainless steel.

\section{Conclusion}

1) The main reasons for cracking of connecting lever are aging cracking and stress corrosion cracking caused by improper processing technology. It is suggested to replace hexagonal connecting lever with round steel connecting rod and strengthen the quality inspection of stainless steel parts.

2) The main reason for the damage of the universal joint is the wrong use of the material. The design material is forged $0 \mathrm{Cr} 18 \mathrm{Ni}$, while the actual use material is cast $\mathrm{ZG0Cr} 18 \mathrm{Ni9}$ which makes the mechanical properties of the part lower than the design requirements. It is recommended to replace all the universal joints in the same batch, and to strengthen the inspection of not replacing in time.

\section{Acknowledgments}

This work was supported by the Science and Technology Foundation of State Grid Corporation of China (Contract No.SGZJ0000KXJS1800302) : Research on metallic material Selection, Manufacturing, Installation Process for Power Transmission and Transformation Equipment and Nondestructive Detection Method for Components.

\section{References}

1. Z.H.Wang, X.M.He, W.Q.Chen, G.F.Liu, L.Wang, Y.Jiang, QingHai Elec. Power 34, 3(2015).
2. Z.W.Cheng, M.K.Yang, H.M.Ma, S.He, X.Zheng, C.J.Xiao, Y.J.He, High Vol. Apparatus 55, 7(2019).

3. J.G.Tu, X.L.Li, F.Huang, X.Q.Wu, Heat Treatment Techno. Equip. 35,1 (2014).

4. Y.Wang, Y.J.Wang, H.Chen, X.M.Tan, T.Zhang, Inner Mongolia Elec. Power 36, 5(2018).

5. Z.L.Dong, P.Hu, X.Luo, Mecha. Elec.Eng. Techno. 46, 2(2017).

6. J.H.Ju, Y.P.Yu, S.A.Li, Low Vol. Apparatus 23,1(2013)

7. Y.Y.Chen, G.Xu, P.K.Yuan, L.F.Shi, S.R.Li, Z.Y.Zhou, C.J.Yao, Mecha. Elec.Eng. Techno. 48, 9(2019). 